Title:

Ultrasensitive Nucleic Acid Sequence Detection by Single-Molecule Electrophoresis

Author(s):

Alonso Castro, P-21

E. Brooks Shera, P-21/AFF

Submitted to:

DOE Office of Scientific and Technical Information (OSTI)
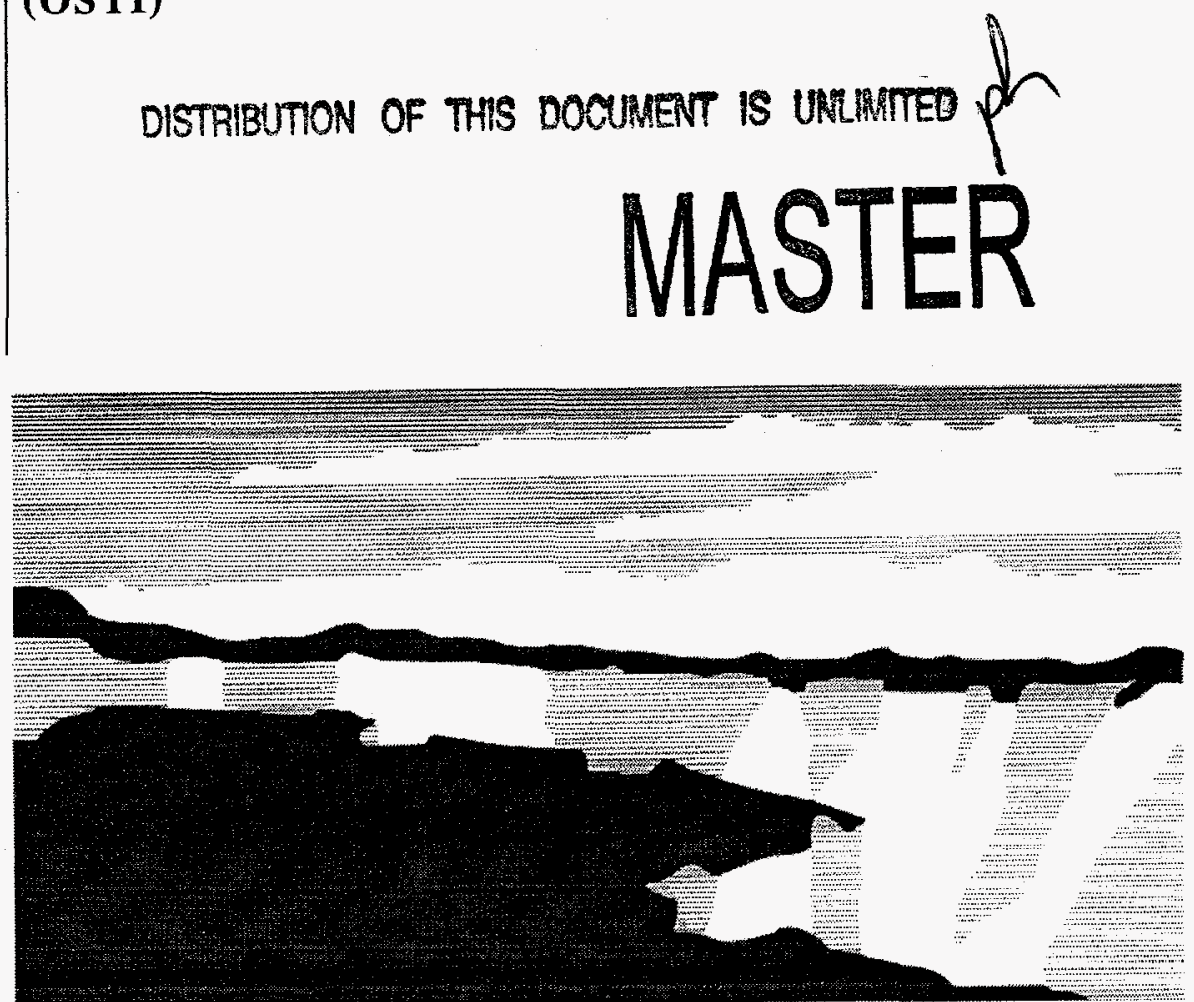

Los Alamos National Laboratory, an affirmative action/equal opportunity employer, is operated by the University of California for the U.S. Department of Energy under contract W-7405-ENG-36. By acceptance of this article, the publisher recognizes that the U.S. Government relains a nonexclusive, royaltyfree license to publish or reproduce the published form of this contribution, or to allow others to do so, for U.S. Government purposes. The Los Alamos National Laboratory requests that the publisher identify this article as work performed under the auspices of the U.S. Department af Energy. 


\section{DISCLAIMER}

Portions of this document may be illegible in electronic image products. Images are produced from the best available original document. 


\section{DISCLAIMER}

This report was prepared as an account of work sponsored by an agency of the United States Government. Neither the United States Government nor any agency thereof, nor any of their employees, makes any warranty, express or implied, or assumes any legal liability or responsibility for the accuracy, completeness, or usefulness of any information, apparatus, product, or process disclosed, or represents that its use would not infringe privately owned rights. Reference herein to any specific commercial product, process, or service by trade name, trademark, manufacturer, or otherwise does not necessarily constitute or imply its endorsement, recommendation, or favoring by the United States Government or any agency thereof. The views and opinions of authors expressed herein do not necessarily state or reflect those of the United States Government or any agency thereof. 


\title{
Ultrasensitive Nucleic Acid Sequence Detection by Single-Molecule Electrophoresis
}

\author{
Alonso Castro* and E. Brooks Shera
}

\begin{abstract}
This is the final report of a one-year Laboratory-Directed Research and Development (LDRD) project at the Los Alamos National Laboratory (LANL). There has been considerable interest in the development of very sensitive clinical diagnostic techniques over the last few years. Many pathogenic agents are often present in extremely small concentrations in clinical samples, especially at the initial stages of infection, making their detection very difficult. This project sought to develop a new technique for the detection and accurate quantification of specific bacterial and viral nucleic acid sequences in clinical samples. The scheme involved the use of novel hybridization probes for the detection of nucleic acids combined with our recently developed technique of single-molecule electrophoresis. This new system is much more sensitive, reliable, and quantitative than current methods.
\end{abstract}

\section{Background and Research Objectives}

Screening for specific nucleic acid sequences with high sensitivity is of fundamental importance in the early-stage diagnosis of bacterial or viral infection, in the detection of genes associated with genetic disorders, and in the detection of early-stage tumor development. Current serological and immunological techniques applied to the analysis of clinical samples are often problematic due to antigenic variability, the time course of presentation, and persistence after an infection has passed an acute stage. In addition, traditional methods often involve the use of radioisotopes, which bear undesirable environmental and health effects. But the most important drawback of current methods is the lack of adequate sensitivity, which makes quantitative detection difficult. In many cases, the specific sequence is present at concentrations so small that detection is impossible.

\footnotetext{
* Principal investigator, e-mail: acx@lanl.gov
} 
The objective of this research project was to demonstrate the initial steps required for the development of a method for the detection and quantitation of specific nucleic acid sequences. The method was based on our established single-molecule electrophoresis detection technique. The sensitivity of this system (i.e., single molecules) is many orders of magnitude greater than that of conventional methods and represents an enormous step in the effort for enhancing the sensitivity of analytical instruments.

\section{Importance to LANL's Science and Technology Base and National R\&D Needs}

The rapid detection of specific nucleic acid sequences with high sensitivity has many applications in a wide variety of fields, such as medical diagnosis, biotechnology, and forensic analysis. All of these fields will benefit from the unprecedented sensitivity of our technique. Biomedical companies, for example, are interested in increasing the sensitivity and quantitation capabilities of diagnosis methods for the screening of genetic and malignant disease and for the analysis of infectious disease. The detection of specific nucleic acid sequences is also important in the biotechnology/agricultural field. Agricultural companies are interested in rapid and ultra sensitive screening techniques applied to genetically engineered products.

This project is directly relevant to the DOE's Defense Programs strategic directions in the area of biological warfare counter-proliferation. The implementation of the technique will allow the development of an instrument capable of real-time monitoring of pathogenic agents in environmental samples. This project supports the Laboratory's core competencies in earth and environmental systems as well as bioscience and biotechnology. It also enhances LANL's ability to respond to initiatives involving ultra sensitive detection technology.

\section{Scientific Approach and Results to Date}

The single-molecule electrophoresis (SME) technique consists of measuring the electrophoretic velocities of individual molecules in solution under an applied electric field and subsequent identification by comparison with the electrophoretic velocity characteristic to a particular molecular species. The basis of our approach is to monitor for the presence of a specific DNA or RNA base sequence that is uniquely characteristic of a particular disease agent or gene. For this purpose, a fluorescent nucleic acid probe that contains a complementary sequence to that of the nucleic acid under analysis is synthesized. When 
combining this probe with the sample containing the target nucleic acid, a process called hybridization occurs, where target and probe are tightly bound due to the complementary nature of their sequences. Analysis of the sample by single-molecule electrophoresis yields two electrophoretic velocity distributions, corresponding to the probe-target complex and the unbound probe. If the particular nucleic acid sequence sought is not present, no probetarget complex peak is observed. We have successfully demonstrated the determination of the electrophoretic velocity of a labeled oligonucleotide with single-molecule sensitivity. A 33-mer oligonucleotide labeled with tetramethylrhodamine at a concentration of $5 \mathrm{fM}$ in TBE buffer was used in the present experiments. Attempts to use hydroxypropyl methyl cellulose (HPMC) as sieving medium did not produce adequate separation efficiencies over a large range of HPMC concentrations. Use of Bio-Rad's sieving buffer produced excellent signal-to-noise ratios and separation efficiencies for the 33-mer oligonucleotide. Other experimental conditions, such as buffer composition and $\mathrm{pH}$, electric field strength, sieving medium concentration, and laser power, were adjusted in order to obtain the best signal-tonoise ratio. The results are shown in Figure 1. These experiments represent the first demonstration of the detection of a short DNA oligonucleotide with single-molecule sensitivity. The detection of probe-target hybrids should also be feasible. 


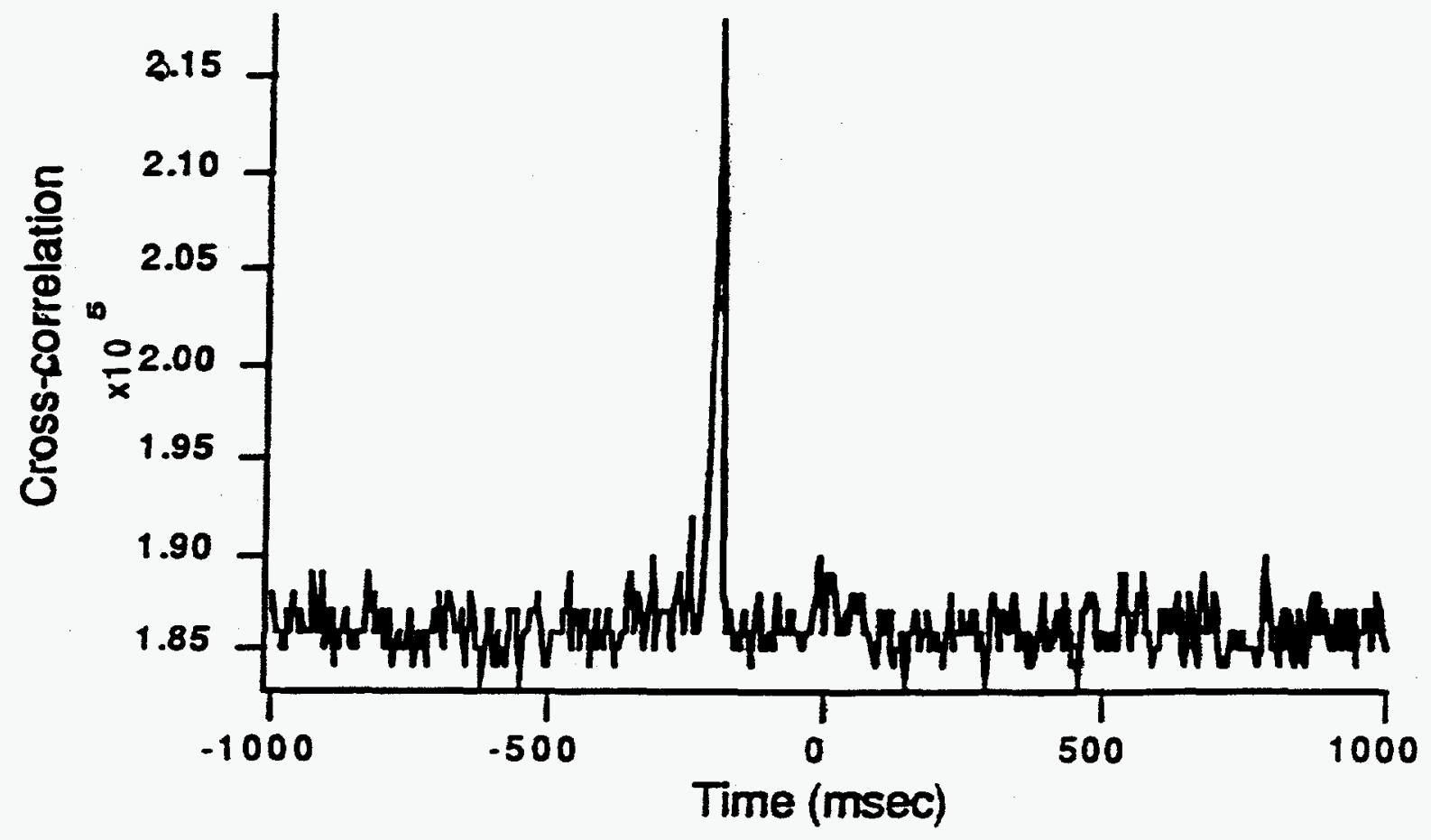

Figure 1. Cross-correlation between the two detector signals for a $5 \mathrm{fM}$ solution of 33mer-tetra-methylrhodamine in TBE buffer/sieving medium. 